\title{
Facilities Management: Physical Built Environmental Factors that Influence User Performance in an Office Building
}

\author{
Asad Jalal Sindhu' ${ }^{1}$ and Kassim Gidado ${ }^{2}$
}

\begin{abstract}
In a generic sense, all services and core products are delivered to the users in a manmade space called 'facility' that serves the organization to deliver its core business objectives. Effective, efficient and comfortable working environment improves quality of life, wellbeing and perceived satisfaction of the user which improves performance to achieving the organisation's goal. The appropriate configuration of the built environmental factors of a facility helps create a pleasant indoor environment and therefore have influential characteristics to dominate user's productivity and performance.

It is evident that quality of the built environmental factors will encourage users' healthy working style and improve uses' wellbeing. Facilities Management of an office building is an integrated approach that maintains, improves and adapts the built environment to support the primary business objectives of the organization. It is about managing user perceived satisfaction and includes the desire to provide a pleasant experience for the users of the facility in order to improve performance. In an organisation ( $\mathrm{SMEs}^{3}$ in the UK), the role of the manipulation of the nature of the facility is one of the primary objectives of a facilities manager for improved user's performance and consequently the overall organizational performance. This research paper therefore aims to identify the key built environmental factors that influence the office building users towards improving their performance in a business enterprise. Quantitative research methodology has been adopted using questionnaires survey tool for this paper. The built environmental factors have been measured by the user on the basis of quality, their perceived satisfaction and the effect on their performance to establish a ranking order of significance.
\end{abstract}

Keywords: facilities management, users' performance, office building, built environment.

\section{Introduction}

This research paper briefly introduces the facility (facility in the context of this paper is an office building of an SME), facilities management (functionality/operations mechanism) and the built environmental factors (BEFs) that influence users' perceived satisfaction and performance. Literature search regarding the office building, employee's performance, facility management have been carried out to develop an understanding of the relationship between the users and the facility to identify the key BEFs of the facility in an organisational environment. A questionnaire survey has been conducted about the user's

\footnotetext{
${ }^{1}$ University of Brighton, U.K. Email: a.sindhu@brighton.ac.uk

${ }^{2}$ University of Brighton, U.K. Email: k.i.gidado@brighton.ac.uk

${ }^{3}$ Small to medium business enterprises in the United Kingdom
} 
perceived satisfaction towards the BEFs and how these factors affect their performance. This paper produced a hierarchical list of the built environmental factors established through the questionnaire survey. Targeted participant of this research were users (employees/staff members) of a small to medium business enterprise using office buildings located and operating within the United Kingdom (UK).

COBE and BCO (2005), Codinhoto (2008) and Oseland (2004) have used quantitative methods to study the BEFs affecting users of various facilities. This paper adopts the same quantitative approach. A questionnaires survey had been designed to initially confirm the built environmental factors identified through the literature review. Physical work environment satisfaction questionnaire (PWESQ) and post occupancy evaluation (POE) methods have been used to develop the questionnaire. The questionnaires were sent out using link of an online survey tool (Survey Monkey ${ }^{\mathrm{TM}}$ ) and respondents were asked to answer the questions online. Respondents are the professional office users identified through Facilities Management Association (FMA) and Interserve Plc, UK. 144 responses were received and analysed using Statistical Package for the Social Sciences (SPSS).

\section{Literature review}

\section{Facility as an active support to the business}

Frontczak et al (2012) states that the contemporary users of the built environment spend $90 \%$ of their lives indoors, which leaves a very serious impact on user's well-being and their working performance. In a facility, comfortable working environment plays a vital role to improve efficiency, workability, quality of life, wellbeing and level of satisfaction of a user. A facility serves a common purpose which is provision of work space and the services. Facility is a space where users perform and carry out their routine work activities for operational purposes towards achieving organisational core businesses objectives. As a hosting venue these are developed to fulfil the user's needs, administer plans and to coordinate the corporate activities. A facility is a workspace where the processing actions related to the organisation of the business such as information, planning, filing, designing, analysing, supervising, deciding and broadcasting and communications take place, (Arora, 1980 quoted by Kamarulzaman et al, 2011). It provides work space and services to satisfy users' demands and needs in an office building setting, (Tiwari et al, 2010) and Seeley (1995). Generically, it serves the organisation as an active support to promote their business, financially enhances the value, quality and the use of the land provides neighbourhood surrounding, and on commercial scale municipal surroundings, (Callaway et al, 2008). Most office buildings are used for a specific purpose to promote the image of the business (external expression), and as a medium of relations to other business communities and to support effective and improved internal communication CABE (2005).

Most office buildings in the UK are influenced by the North American construction style which has been argued by a number of researchers as not user oriented and have a very low level of user control over the indoor environment. The user's perception towards buildings has been changed and the buildings are not only use for working place but as a meeting point, Kok and Jennen (2012). Modern office buildings are trendy equipped with new technology. They have become more complex and this new wave demands organisations to pay more considerations to the users of the facility and to the ever changing information technology, IFMA (2012). 
A facility provides suitable space with the help of facilities management to make the experience and working activities of the users as smooth as possible.

\section{The facilities management (FM)}

Facility management is the integration of processes within an organisation to maintain and develop the agreed services which support and improve the effectiveness of its primary activities and user comforts. 1960 is the year when the term facilities 'management (FM) was used for the very first time Wiggins (2011:1). Facilities management reflects the organisations nature and purpose of the businesses. It is an integrated approach to operating, maintaining, improving and adopting the facility and the infrastructure of an organisation in order to create an environment that supports the primary objective of the organisation, Price et al (2001). It plays a central role in the maintenance and operation of a facility, Alexander (2007). It encompasses multiple disciplines to ensure functionality of the built environment by integrating people, place, processes and the technology.

Better user performance the facility is attainable with better facilities management system. It is not just the design, layout of the office building which can impact the user performance but the way office building is managed also have its role to play, Haynes (2011) quotes Clements-Croome (2003). Facilities Management can be classed as a quality control department in the facility, an integrated approach to maintaining, improving and adapting the built environment to accurately reflect and to directly support the primary business objectives of the organization. It is about managing users and their perceived satisfaction with an intention and desire to provide them a pleasant experience to gain an improved performance. It is the management of people and the facility, making available resources useful and utilizing them properly, ensuring to make user's experience unique by providing services excellence and making organization's image encouraging and constructive for users and the community.

\section{Impact of built environment on a facility user}

CABE and BCO (2005) suggest that the performance measurement of both office building and their users can improve the management process, resource allocations, decision making, better regulations and legislative oversight and accountability. Facilities Management is a management of interaction between user and the facility, and control over the BEFs can leave positive or negative impact on user's which ultimately reflects in the organisational performance, (IFMA). In the facility built environmental factors (BEFs) create indoor environment, and better indoor environment encourage users healthy working style and improve their performance.

Along with physical BEFs there are some non-physical built environmental factors which can be influential on user's performance and cannot be ignored such as, climate change or global warming, gender, culture, religion, etc. Stenberg (1995) Redman et al (2009) Wang et al (2008) consider that there is a variation of affects depending on the sociodemographic role of the user such as age, qualification or marital status etc, Ajala (2012), Lagoudi et al (1996). The most important non-physical BEFs are, new legislation, political/organisational pressure groups, climate change, motivation, relationship with higher management, moral, health and safety, social, self-actualisation, gender, age, religion, sick building syndrome (SBS), etc., Butt et al (2013), Redman et al (2011) and Wang et al (2008). These non-physical environmental factors of a facility are beyond the scope of this paper, therefore will not be discussed any further. 


\section{Physical Built Environmental Factors in an Office Building}

Healthy working environment encourages healthy working style and reduces absenteeism at work. In a manmade built environment comfortable working environment plays a vital role to improve efficiency, workability, quality of life, wellbeing and level of satisfaction of a user, Fanger (2000). The indoor environmental quality (IEQ) has a major and positive impact on the performance of the office workers, Fanger (2001), and the IEQ should be acceptable to all the users in the office building, Frontczak et al (2011), Dorgan and Dorgan (2005) and Ajala (2012). As stated earlier, an office building user spends almost half of their life at their work place, therefore, it is vital to keep a user satisfied with the indoor environmental quality (IEQ), Frontczak et al (2011), Dorgan and Dorgan (2005) and Ajala (2012). The built environmental factors make the indoor environment usable and to support users functional tasks. BEFs can be divided into four major factors, i.e., aesthetics, ambient, ergonomics, and services, Codinhoto et al (2009), Danielson and Bodin (2009). Chuck and Jeong (2012) add fabric (quality, durability, materials) into this list. Therefore, the major BEFs are; aesthetics (colour, art, layout, design), fabric (façade, surface, quality, durability, materials, lighting, acoustics, temperature, humidity), ambient (acoustic level, noise, air, lighting), ergonomics (furniture layout, IT station, hot desks, offices dimensions, shapes, lay out), and the services (operation, maintenance, accessibility, management, cleanliness, decontamination), Chuck and Jeong (2012), Codinhoto et al (2009), Munirathinam et al (2011), Vischer (2008). Instead of using BEFs, Leaman and Bordass (2000) use the term 'the killer variables'. The killer variables have a serious influence on user's perceived satisfaction and performance in an office building and the overall system in the facility. They have identified five variables:

1. perceived comfort and control over personal environment

2. response towards the needs, including comfort

3. ventilation types

4. workgroups and the layout and space plan

5. design (durability, quality, materials used)

\section{Questionnaire survey}

Comfortable working environment plays a vital role to improve users' efficiency, workability, quality of life, the wellbeing and level of user's perceived satisfaction. Users' satisfaction and experience towards the services provided at work is a growing area of interest amongst the employers, Vischer (2008). The questions asked in this survey were related to the user's personal experience and their perceived satisfaction with the services. This questionnaire survey had a very good response from the industry and many facilities management organisations have shown their interest in the research findings. A hierarchical list of the key BEFs has been established. This is shown in Table presented in the end of this paper. As adopted from Gidado and Akelere (2003) and Frontczak (2011), the Severity Index formula has been used for ranking the BEFs, i.e.,

$\mathrm{S} . \mathrm{I}=\sum \frac{R w W}{R t}$

Where: $\mathrm{R}_{\mathrm{W}}=$ number of respondents; $\mathrm{W}=$ weighting or points assigned; $\mathrm{R}_{\mathrm{t}}=$ total number of responses obtained for the variable. Likert scale considered for measure of severity is: no effect $=1$, low effect $=2$, medium effect $=3$, high effect $=4$, critical effect $=5$ 


\begin{tabular}{|c|c|c|c|c|c|c|}
\hline \multicolumn{7}{|c|}{ List of Built Environmental Factors } \\
\hline $\begin{array}{l}\text { Sr. } \\
\text { No. }\end{array}$ & Type & Built Environmental Factors & $\begin{array}{l}\text { Response } \\
\% \text { age }\end{array}$ & $\begin{array}{l}\text { Response } \\
\text { Count }\end{array}$ & $\begin{array}{l}\text { Skip } \\
\text { ped }\end{array}$ & $\begin{array}{l}\text { Severit } \\
\text { y Index }\end{array}$ \\
\hline 38 & Ix. BEFs & $\begin{array}{l}\text { Suitable level of lighting to perform your } \\
\text { routine activities }\end{array}$ & 76.39 & 110 & 34 & 3.94 \\
\hline 30 & Ix. BEFs & $\begin{array}{l}\text { Air quality (emission of gases, outdoor } \\
\text { pollution, dust in the air, moisture etc.) }\end{array}$ & 75 & 108 & 36 & 3.93 \\
\hline 29 & Ix. BEFs & Fresh air circulation at your work place & 75.69 & 109 & 35 & 3.92 \\
\hline 43 & Ix. BEFs & $\begin{array}{l}\text { Overall cleaning and maintenance of the } \\
\text { communal facilities and the area }\end{array}$ & 77.08 & 111 & 33 & 3.92 \\
\hline 31 & Ix. BEFs & Poor ventilation system in the office & 76.39 & 110 & 34 & 3.88 \\
\hline 39 & Ix. BEFs & $\begin{array}{l}\text { Communications system to report a fault } \\
\text { regarding these factors }\end{array}$ & 75.69 & 109 & 35 & 3.85 \\
\hline 32 & Ix. BEFs & Poor management and maintenance & 75.69 & 109 & 35 & 3.84 \\
\hline 4 & Ex. BEFs & Traveling time to your work place & 85.42 & 123 & 21 & 3.76 \\
\hline 24 & Ix. BEFs & $\begin{array}{l}\text { Furniture suitable, adjustable, rearrange able, } \\
\text { re-organisable (in terms of layout and design } \\
\text { flexibility in the space) }\end{array}$ & 80.56 & 116 & 28 & 3.76 \\
\hline 35 & Ix. BEFs & Lighting provided in your office & 75.69 & 109 & 35 & 3.75 \\
\hline 5 & Ex. BEFs & Traveling cost to your work place & 84.03 & 121 & 23 & 3.73 \\
\hline 26 & Ix. BEFs & $\begin{array}{l}\text { Individual control over temperature regarding } \\
\text { settings/adjusting its level }\end{array}$ & 75.69 & 109 & 35 & 3.73 \\
\hline 22 & Ix. BEFs & $\begin{array}{l}\text { Lay out/setting/ design is suitable to perform } \\
\text { day to day activity }\end{array}$ & 81.94 & 118 & 26 & 3.72 \\
\hline 25 & Ix. BEFs & $\begin{array}{l}\text { Central heating and air circulation system } \\
\text { (HVAC) in your office }\end{array}$ & 77.08 & 111 & 33 & 3.72 \\
\hline 33 & Ix. BEFs & Natural lighting in your office & 77.08 & 111 & 33 & 3.69 \\
\hline 46 & Ix. BEFs & Solving the maintenance issues & 76.39 & 110 & 34 & 3.67 \\
\hline 47 & Ix. BEFs & $\begin{array}{l}\text { Response handling (response time to rectify } \\
\text { the maintenance issues) }\end{array}$ & 76.39 & 110 & 34 & 3.67 \\
\hline 17 & Ex. BEFs & $\begin{array}{l}\text { Building design is suitable for the } \\
\text { organisational purpose }\end{array}$ & 86.11 & 124 & 20 & 3.65 \\
\hline 23 & Ix. BEFs & $\begin{array}{l}\text { Enough storage space for your working tools } \\
\text { and equipment }\end{array}$ & 81.94 & 118 & 26 & 3.64 \\
\hline 34 & Ix. BEFs & Artificial lighting in your office & 77.08 & 111 & 33 & 3.64 \\
\hline 28 & Ix. BEFs & Odours in the air & 76.39 & 110 & 34 & 3.62 \\
\hline 36 & Ix. BEFs & Individual control over lighting & 76.39 & 110 & 34 & 3.59 \\
\hline 42 & Ix. BEFs & Provision of tea, coffee, refreshments, etc. & 77.08 & 111 & 33 & 3.53 \\
\hline 44 & Ix. BEFs & Provision of security services & 77.08 & 111 & 33 & 3.47 \\
\hline 37 & Ix. BEFs & $\begin{array}{l}\text { Individual control over opening a window to } \\
\text { get the natural light }\end{array}$ & 76.39 & 110 & 34 & 3.39 \\
\hline 7 & Ex. BEFs & Parking space for the building users & 82.64 & 119 & 25 & 3.36 \\
\hline
\end{tabular}




\begin{tabular}{|c|c|c|c|c|c|c|}
\hline 40 & Ix. BEFs & Break out areas & 77.08 & 111 & 33 & 3.35 \\
\hline 48 & Ix. BEFs & Acoustics in break out areas (less noisy) & 76.39 & 110 & 34 & 3.33 \\
\hline 9 & Ex. BEFs & $\begin{array}{l}\text { Traveling/wait time (waiting time for } \\
\text { transport to get to your work) }\end{array}$ & 84.03 & 121 & 23 & 3.31 \\
\hline 18 & Ex. BEFs & $\begin{array}{l}\text { Building facade and shading is suitable to } \\
\text { cope with climatic changes }\end{array}$ & 85.42 & 123 & 21 & 3.3 \\
\hline 41 & Ix. BEFs & $\begin{array}{l}\text { Quality of products and services provided in } \\
\text { the break out areas }\end{array}$ & 77.08 & 111 & 33 & 3.3 \\
\hline 3 & Ex. BEFs & Accessibility to public transport & 84.72 & 122 & 22 & 3.29 \\
\hline 27 & Ix. BEFs & $\begin{array}{l}\text { Individual control over opening/operating } \\
\text { windows }\end{array}$ & 76.39 & 110 & 34 & 3.22 \\
\hline 21 & Ix. BEFs & $\begin{array}{l}\text { Internal Way-finding (to find a room/office) } \\
\text { is easy }\end{array}$ & 81.25 & 117 & 27 & 3.21 \\
\hline 10 & Ex. BEFs & $\begin{array}{l}\text { Noisy (outside traffic and other noise } \\
\text { pollution of the area) }\end{array}$ & 84.72 & 122 & 22 & 3.19 \\
\hline 13 & Ex. BEFs & $\begin{array}{l}\text { Represent the main business of the } \\
\text { organisation }\end{array}$ & 86.11 & 124 & 20 & 3.19 \\
\hline 19 & Ix. BEFs & $\begin{array}{l}\text { Internal layout represent the organisation's } \\
\text { culture and values }\end{array}$ & 81.94 & 118 & 26 & 3.19 \\
\hline 12 & Ex. BEFs & $\begin{array}{l}\text { Represent the organisation's culture and } \\
\text { values }\end{array}$ & 85.42 & 123 & 21 & 3.11 \\
\hline 11 & Ex. BEFs & $\begin{array}{l}\text { Outside view ( roads, streets, civic centre, } \\
\text { etc.) }\end{array}$ & 84.72 & 122 & 22 & 3.1 \\
\hline 8 & Ex. BEFs & $\begin{array}{l}\text { Outside view (surroundings: nature, } \\
\text { horticulture, etc.) }\end{array}$ & 84.03 & 121 & 23 & 3.07 \\
\hline 6 & Ex. BEFs & Way-finding to the building & 83.33 & 120 & 24 & 3.04 \\
\hline 1 & Ex. BEFs & Accessible to local amenities & 84.72 & 122 & 22 & 3.01 \\
\hline 16 & Ex. BEFs & $\begin{array}{l}\text { Colour and design of the facade is a depiction } \\
\text { of your organisation }\end{array}$ & 86.11 & 124 & 20 & 2.95 \\
\hline 20 & Ix. BEFs & $\begin{array}{l}\text { Colour scheme used inside the building } \\
\text { matches the colour of the organisation }\end{array}$ & 81.94 & 118 & 26 & 2.94 \\
\hline 15 & Ex. BEFs & Aesthetically perfect design & 86.11 & 124 & 20 & 2.9 \\
\hline 2 & Ex. BEFs & In the middle of city centre & 84.03 & 121 & 23 & 2.84 \\
\hline 14 & Ex. BEFs & $\begin{array}{l}\text { Office building as an iconic symbol for the } \\
\text { community and culture }\end{array}$ & 86.81 & 125 & 19 & 2.84 \\
\hline 45 & Ix. BEFs & $\begin{array}{l}\text { Provision of games/equipment for physical } \\
\text { activities in the break out area }\end{array}$ & 76.39 & 110 & 34 & 2.77 \\
\hline
\end{tabular}

Ex. BEFs: External expression of an office building

Ix. BEFs: Internal Expression of the an office building

BEFs: Built environmental factors

Total No of respondents: 144 


\section{Discussion}

Literature review identifies almost 48 BEFs in a facility (Sr. No. 1 to 48) as shown in Table 1. An attempt has been made through a questionnaire survey to show the BEFs on a significance scale according to the user's perceived satisfaction and experience. Questions asked in this survey were related to the user's personal experience and their perceived satisfaction with the services. This questionnaire survey had a very good response from the industry and many facilities management organisations have shown their interest in the research findings. Generally, the questions related to indoor environment fetched higher score as compare to other built environmental factors. Previous studies suggested that the satisfaction and performance are critically influenced by the indoor built environmental factors; for example lighting (natural or artificial), HVAC, storage and privacy, external view through the window, etc., Codinhoto et al (2008), Sundstrom et al (1996), Voordt (2004), Unzeitig and Madhavi (2005). As stated earlier this questionnaire was divided into two sections (i) external expressions (Ex. BEFs) and (ii) internal expressions (Ix. BEFs). Table 1 shows that on the severity index scale external built environmental factors have also gained ranking amongst the top 20 ranking based on the users perceived satisfaction and their experience. The Table 1 shows that Ix. BEFs are not the only key factors that affect the users' perceived satisfaction and performance, but also the Ex. BEFs, time and the cost of traveling to the work place in particular.

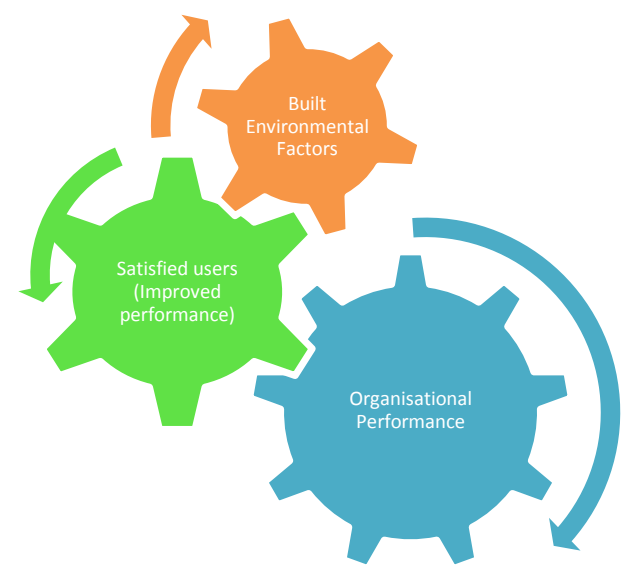

Figure 1: A conceptual model of user's perceived satisfaction mechanism

\section{Conclusion}

This paper has achieved three main goals; a list of 48 BEFs as shown in Table 1. This list of BEFs could be useful for analysing physical work environment satisfaction (PWES) and post occupancy evaluation (POE). It presents the top 10 most critical BEFs. This paper has also established that researchers and the facilities managers overlook the external BEFs. However, based on the questionnaire data this paper identified critical external BEFs that cannot be overlooked by the facilities mangers at the time of decisions making about the facility. The ranking of the BEFs may be limited to UK, but the identified key factors should apply beyond the UK as long as it is within an office environment. 


\section{References}

Callaway S Z (2008), 'Modern Office’, Fortune International (Europe), Vol. 158 Issue 1.

Chuck W F and Jeong T K (2012) 'Sustainable Developments for Future Building', Indoor and Built Environment, Vol. 21, Issue 3.

Codinhoto R et al (2009) 'The impact of the Built Environment on Health Outcome', Facilities, Vol. 27, Iss. 3/4, pp 138-151.

Danielsson C B and Bodin L (Autumn 2009), 'Difference in Satisfaction with Office Environment among Employees in Different Office Types', Journal of Architectural and Planning Research Vol. 26, Issue 3.

Fanger P O (2001) 'Human Requirements in Future Air-Conditioned Environment', International Journal of Refrigeration Vol. 24. Pp. 148-153.

Frontczak M (2011) 'Questionnaire Survey on Factors Influencing Comfort with Indoor Environmental Quality in Danish Hosing, International Centre for Indoor Environment and Energy', Deptt; of Civil Engineering, Technical University of Denmark.

Gidado, K and Akelere, D (2003), The risks and constraints in the implementation of PFI/PPP in Nigeria. Proceedings of the 19th Annual Conference of the Association of Researchers in Construction Management, Univ of Brighton, 3-5 Sept. Vol 1 p. 379-392.

Jennen M and Kok N (2012), 'The Impact of Energy Labels and Accessibility on Office Rents', Journal of Energy Policy, Elsevier, Vol. 49. Pp 489-497.

Kamarulzaman A, Saleh A, and Hashim SZ (2011), 'An Overview of the Influence of Physical Office Environments towards Employees', Procedia Engineering, V 20, 262 - 268.

Munirathinam N T and Ramesh G (2011) 'Achieving Organisational Effectiveness through Health Management and Ergonomics’, Advances in Management, Vol. 4 iss. 4.

Oseland N (2004), 'Occupant Feedback Tools of the Office Productivity', proceedings of Closing the Loop, April 2004, pp. 1-12.

Price S and Pitt M (2011), 'Implication of a Sustainability Policy for Facilities Management Organisations', Emerald Journal of Facilities, vol. 29 No. 9/10. Pp 391-410.

Pritchard R D and Jones S D (1989) 'the Evaluation of an Integrated Approach to Measuring Organisational Productivity Personnel Psychology, Vol. 42, pp 69-115.

The Chartered Association of Building Engineers (CABE) and British Council for Office Buildings (BCO) (2005), 'the impact of Building Design on Business Performance, Commission for Architecture and Built Environment and the British Council for Offices.

Tiwari R, Pandey M and Sharma A (2010), 'an Approach to Human Adaptability towards its Built Environment: A Review’, Energy and Power Engineering', Vol. 2, p.p. 90-94.

Vischer J C (2008) 'Towards a User-Centered of the Built Environment', Building Research and Information, Vol. 36, Iss. 3, pp 231-241.

Wiggin J M (2011), ‘Facilities Manager’s Desk Reference’, Willey Blackwell, Oxford. 